\title{
Carole Edwards, Les dramaturges antillaises. Cruauté, créolité, conscience féminine
}

\section{Luigia Pattano}

\section{Q OpenEdition}

1 Journals

\section{Edizione digitale}

URL: http://journals.openedition.org/studifrancesi/8406

DOI: 10.4000/studifrancesi.8406

ISSN: 2421-5856

\section{Editore}

Rosenberg \& Sellier

\section{Edizione cartacea}

Data di pubblicazione: 1 mai 2009

Paginazione: 219-220

ISSN: 0039-2944

\section{Notizia bibliografica digitale}

Luigia Pattano, «Carole Edwards, Les dramaturges antillaises. Cruauté, créolité, conscience féminine»,

Studi Francesi [Online], 157 (LIII | I) | 2009, online dal 30 novembre 2015, consultato il 14 janvier 2021. URL: http://journals.openedition.org/studifrancesi/8406 ; DOI: https://doi.org/10.4000/studifrancesi. 8406

Questo documento è stato generato automaticamente il 14 janvier 2021.

\section{(c) 9 (i) $\Theta$}

Studi Francesi è distribuita con Licenza Creative Commons Attribuzione - Non commerciale - Non opere derivate 4.0 Internazionale. 


\title{
Carole Edwards, Les dramaturges antillaises. Cruauté, créolité, conscience féminine
}

\author{
Luigia Pattano
}

\section{NOTIZIA}

CAROLE EDWARDS, Les dramaturges antillaises. Cruauté, créolité, conscience féminine, Paris,

L'Harmattan, 2008, pp. 202.

1 Omaggio alle autrici di teatro delle Antille, dimenticate se non volutamente offuscate, secondo Carole Edwards, dagli scrittori e dai critici, il saggio si propone di definire alcune linee direttrici della drammaturgia femminile di quest'area a partire dall'analisi di nove pièces e di alcuni concetti teorici legati al teatro, alla teoria postcoloniale e al femminismo. I testi presi in esame sono: Dieu nous l'a donné (1972), Mort d'oluwémi d'Ajumako (1973) e Pension les Alizés (1988) di Maryse Condé, Ton beau capitaine (1987) di Simone Schwarz-Bart, Lettres indiennes (1993) di Gerty Dambury, Mémoire d'Isles Maman N. et Maman F. (1985) e L'enfant des passages ou la geste de Ti-Jean (1987) di Ina Césaire, Nef (1992) di Michèle Césaire e Lumina Sophie dite Surprise (2005) di Suzanne Dracius. Malgrado la loro eterogeneità sotto il profilo strutturale, le pièces presentano alcuni tratti comuni che Carole Edwards legge, nel primo capitolo, come elementi di un teatro della crudeltà. Al pari di quello teorizzato da Artaud, questo teatro sarebbe crudele in quanto consente la drammatica presa di coscienza della nostra condizione mortale di esseri umani svelando le nostre menzogne e le nostre bassezze e spingendoci al riscatto. Altro elemento che accomuna il lavoro delle drammaturghe prese in esame a quello di Artaud è la natura totale del teatro che non predilige il testo, ma associa alla parola gestualità, musica e canto.

2 Nel secondo capitolo l'autrice passa brevemente in rassegna le grandi correnti teoriche legate alla storia e alla letteratura delle Antille: "Negritudine", "Creolità", "Antillanità" 
e "Creolizzazione". Secondo la Edwards, le scrittrici antillane sono riuscite a superare lo stadio di pre-letteratura, in cui, per i firmatari di Éloge de la Créolité, tuttora si collocherebbe la scrittura letteraria delle Antille, introducendo nei loro scritti la tematica storica e facendosi portavoce della collettività. Tra gli elementi creoli presenti nei testi, quello che predomina è il racconto legato a temi folcloristici quali il carnevale, la superstizione e il travestimento. La Edwards si mostra molto polemica nei confronti della concezione teatrale espressa da Glissant nel Discours antillais e denuncia l'atteggiamento elitario del celebre scrittore che contribuirebbe all'ostracismo di cui sono vittime le scrittrici delle Antille.

Dedicato al tema della scrittura come oggetto di resistenza, il terzo capitolo affronta, attraverso l'analisi dei testi sopra citati, alcune tematiche centrali quali la storia, l'esilio e la libertà. Un'attenzione particolare è rivolta alla pièce di Suzanne Dracius che associa elementi della tradizione greco-romana a elementi della cultura creola. L'ultimo capitolo ha come oggetto i diversi tentativi di classificare la scrittura delle donne e le tematiche legate alla condizione femminile. Quanto al primo punto, dopo essersi soffermata brevemente sulle nozioni di «femminismo» e "womanism», la Edwards suggerisce di adottare l'idea di «coscienza femminile» proposta da Carol Boyce Davies ed Elaine Savory Fido (Out of Kumbla: Caribbean Women and Literature, New Jersey 1990) che non esclude l'apporto complementare di scrittori e critici. Nella seconda parte del capitolo, l'autrice analizza invece le figure femminili presenti nei testi e si sofferma sul rapporto femminilità/maternità in opposizione all'universo maschile.

4 Malgrado la ricchezza di riferimenti che denotano padronanza della materia, le analisi e i giudizi della Edwards risultano talvolta affrettati e troppo drastici. Le questioni prese in esame avrebbero forse richiesto uno spazio e un'attenzione maggiori. Il saggio ha tuttavia il pregio di colmare una lacuna nello studio della letteratura caraibica e fornisce indubbiamente stimoli per ulteriori ricerche. 